\title{
FDA panel recommends approval of deferiprone
}

$\mathrm{E}$ arlier this month, Tony Viola, president of the Cooley's Anemia Foundation, a New York City, New York-based nonprofit advocacy group for people with thalassemia, boarded a bus headed to the United States Food and Drug Administration's (FDA) Silver Springs, Maryland campus, telling colleagues that it was the most important day of his life.

Viola and others at the foundation believe scores of their members have died prematurely, in their 20s and 30s, because a drug intended to treat iron buildup caused by frequent blood transfusions has been too difficult to obtain.

The drug, deferiprone (Ferriprox), an oral iron chelator, became mired in controversy more than a dozen years ago when its developer, Toronto, Ontario-based generics giant, Apotex, put an early stop to a clinical trial led by University of Toronto hematologist Dr. Nancy Olivieri. Many saw the company's move as unethical (CMAJ 2002; 166[4]:487).

But Viola and others, argued during a Sept. 14 meeting of the FDA's Oncologic Drugs Advisory Committee that deferiprone should be approved for use when other similar drugs fail in the treatment of patients with transfusionrelated iron overload.

The lineup in support of approval included Dr. Ellis Neufeld, associate chief of hematology/oncology at Children's Hospital Boston, a pediatric teaching hospital associated with Harvard Medical School in Massachusetts. Neufeld told the FDA committee there are serious problems with the two iron chelators currently in use.

About 25\% of patients on the injection-only drug deferoxamine and $30 \%$ on the oral drug deferasirox fail to respond adequately, according to data from a US National Institutes of Healthfunded research network, Neufeld said.

All major US treatment centres prescribe deferiprone through a compassionate use program and the number of patients on the drug has risen steadily

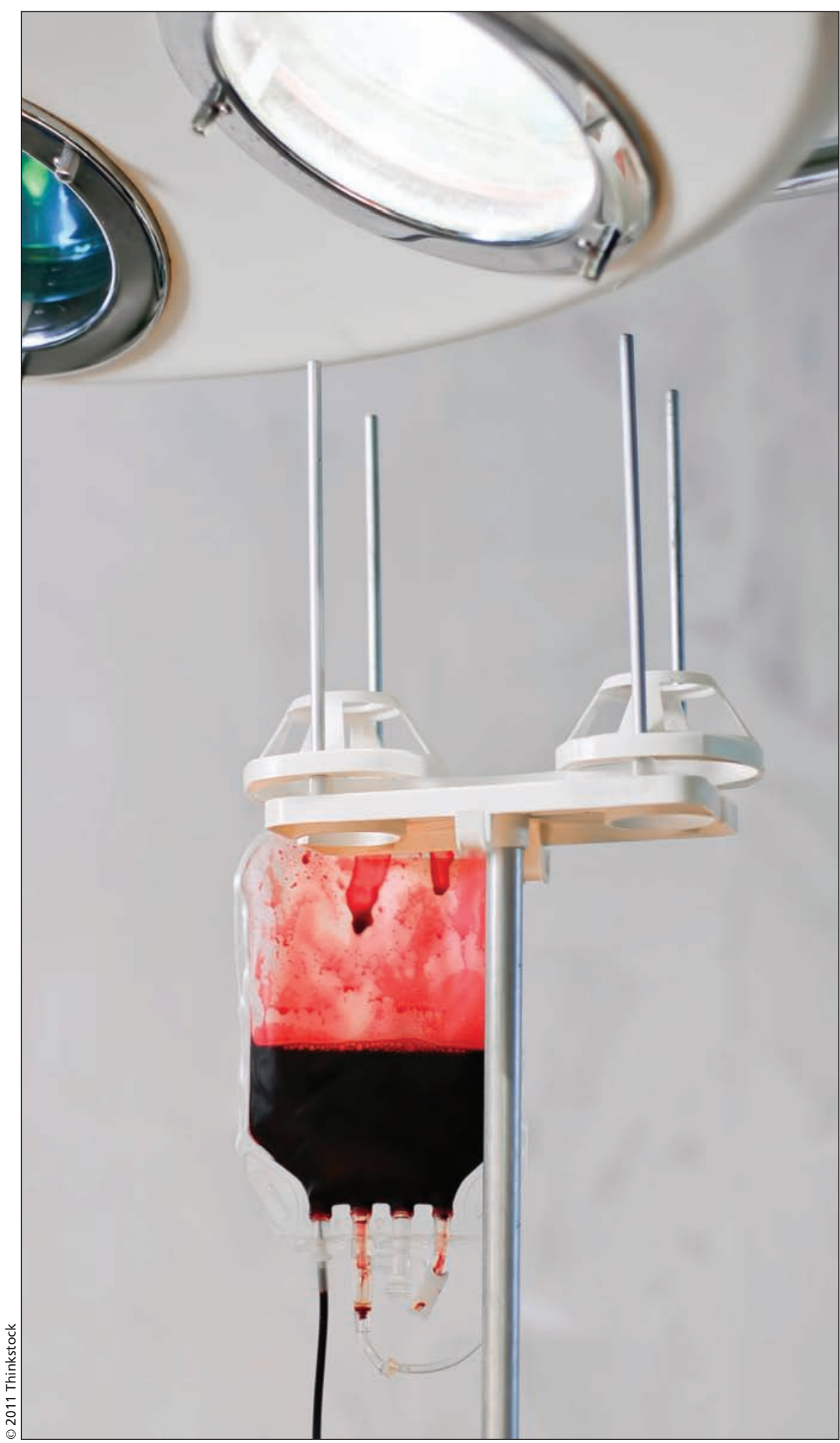

Deferiprone is being administered, on compassionate use grounds, to patients with iron buildup caused by frequent blood transfusions. 
over the past 15 years, Neufeld said, adding that between 2006 to 2010, 52 of the 500 to 1000 US patients who have thalassemia major were on deferiprone.

Deferiprone is also available under a compassionate use program in Canada, Dr. Richard Ward, a hematologist with the Red Blood Cell Disorders Program at the Toronto General Hospital in Ontario, testified during the meeting's open session. Ward indicated his program has prescribed the drug to nearly 40 patients with thalassemia and sickle cell disease, or about $25 \%$ of those treated in the program. The drug enables the program to offer patients a treatment tailored to their own needs, he said.

Olivieri was not at the meeting but made written submissions that ran to 15 pages and listed many different scientific and regulatory concerns about deferiprone (www.fda.gov/downloads /AdvisoryCommittees/CommitteesMeet ingMaterials/Drugs/OncologicDrugs AdvisoryCommittee/UCM271676.pdf).

In an analysis of company data undertaken by FDA scientists, the drug appeared effective in lowering iron levels but it also had a serious risk: in nearly $1.7 \%$ of patients, it wiped out all neutrophils, causing a potentially fatal adverse drug reaction known as agranulocytosis (www.fda.gov/down loads/AdvisoryCommittees/Committees MeetingMaterials/Drugs/Oncologic DrugsAdvisoryCommittee/UCM2715 37.pdf).

ApoPharma, the Apotex subsidiary that now produces deferiprone, acknowl- edged in its presentation (www.fda .gov/downloads/AdvisoryCommittees /CommitteesMeetingMaterials/Drugs /OncologicDrugsAdvisoryCommittee /UCM271538.pdf) that the effect is unpredictable and that 13 patients have died from agranulocytosis during 11 years of postmarketing follow-up in Europe, where the drug was approved for second-line use in 1999. The firm testified that 11 of those deaths occurred before it instituted a program for doctors and patients emphasizing the importance of weekly blood cell counts and the need to stop deferiprone at the first sign of an infection or a drop in white blood cells. It also indicated that it intends to implement such a program in the US.

When it came time for Viola to speak, he chided the committee: "To not approve this drug would almost be akin to restricting the number of years thalassemia patients can live."

Committee members expressed concerns about the lack of data regarding deferiprone's use to treat sickle cell disease and advised ApoPharma to conduct further studies within the population group.

Similarly, Dr. Mikkael Sekeres, a committee member and a staff member in the Department of Hematologic Oncology and Blood Disorders at the Cleveland Clinic Taussig Cancer Institute in Ohio, expressed concern about the use of deferiprone in treating patients with myelodysplastic syndrome.

But ApoPharma indicated that it does want the drug approved for such use and Richard Pazdur, director of FDA's Center for Drug Evaluation and Research's Office of Oncology Drug Products, told the committee that deferiprone's label would clearly state that. But he acknowledged that offlabel use was still possible. (In 2010, FDA required a black box warning for deferasirox after finding that patients with myelodysplastic syndrome who used the drug developed potentially fatal liver and kidney problems and gastrointestinal bleeding).

The advisory committee voted $10-2$ to recommend approval of the drug, with those in favour including Dr. Susan Shurin, acting director of the NIH National Heart Lung and Blood Institute, who explained that she considered its safety profile "adequate" and saw the need for the drug as "very considerable."

ApoPharma touted the vote as "a major achievement" (www.apotex .com/global/about/press/20110914.asp). Company spokesman Elie Betito says the drug has not yet been submitted for Health Canada approval because the firm has been focusing on its FDA application. Should the FDA ratify the advisory committee's recommendation, as it typically does, deferiprone would be approved for use in the US as second-line therapy for patients who suffer from transfusion-related iron overload and have already tried other available chelators. - Miriam Shuchman MD, Toronto, Ont.

CMAJ 2011. DOI:10.1503/cmaj.109-4012 